\title{
Picfeltarraenin IA inhibits lipopolysaccharide-induced inflammatory cytokine production by the nuclear factor- $\kappa B$ pathway in human pulmonary epithelial A549 cells
}

\author{
RONG SHI, QING WANG, YANG OUYANG, QIAN WANG and XUDONG XIONG \\ Department of Emergency Internal Medicine, Shuguang Hospital, \\ Shanghai University of Traditional Chinese Medicine, Shanghai 201203, P.R. China
}

Received January 23, 2015; Accepted November 6, 2015

DOI: $10.3892 / \mathrm{ol} .2015 .4037$

\begin{abstract}
The present study aimed to investigate the effect of picfeltarraenin IA (IA) on respiratory inflammation by analyzing its effect on interleukin (IL)-8 and prostaglandin E2 (PGE2) production. The expression of cyclooxygenase 2 (COX2) in human pulmonary adenocarcinoma epithelial A549 cells in culture was also examined. Human pulmonary epithelial A549 cells and the human monocytic leukemia THP-1 cell line were used in the current study. Cell viability was measured using a methylthiazol tetrazolium assay. The production of IL-8 and PGE2 was investigated using an enzyme-linked immunosorbent assay. The expression of COX2 and nuclear factor- $\kappa \mathrm{B}(\mathrm{NF}-\kappa \mathrm{B})-\mathrm{p} 65$ was examined using western blot analysis. Treatment with lipopolysaccharide (LPS; $10 \mu \mathrm{g} / \mathrm{ml}$ ) resulted in the increased production of IL- 8 and PGE2, and the increased expression of COX2 in the A549 cells. Furthermore, IA $(0.1-10 \mu \mathrm{mol} / \mathrm{l})$ significantly inhibited PGE2 production and COX2 expression in cells with LPS-induced IL-8, in a concentration-dependent manner. The results suggested that IA downregulates LPS-induced COX2 expression, and inhibits IL- 8 and PGE2 production in pulmonary epithelial cells. Additionally, IA was observed to suppress the expression of COX2 in THP-1 cells, and also to regulate the expression of $\mathrm{COX} 2$ via the $\mathrm{NF}-\kappa \mathrm{B}$ pathway in the A549 cells, but not in the THP-1 cells. These results indicate that IA regulates LPS-induced cytokine release in A549 cells via the NF- $\kappa$ B pathway.
\end{abstract}

Correspondence to: Professor Qian Wang or Professor Xudong Xiong, Department of Emergency Internal Medicine, Shuguang Hospital, Shanghai University of Traditional Chinese Medicine, 528 Zhangheng Road, Shanghai 201203, P.R. China

E-mail: tazhouqm@163.com

E-mail: doctorxiong@126.com

Key words: picfeltarraenin IA, interleukin-8, prostaglandin E2, cyclooxygenase 2 , nuclear factor- $\kappa \mathrm{B}$ pathway

\section{Introduction}

Picfeltarraenin IA (IA) is extracted from the plant Picria fel-terrae Lour and has been used in traditional Chinese medicine as an acetylcholinesterase inhibitor (1). However, little is understood of the mechanisms underlying the beneficial properties of IA that are exploited today in the treatment of respiratory diseases.

Inflammation is a defense mechanism that arises to remove injurious stimuli. However, prolonged inflammation may lead to various disorders, including respiratory diseases (2). Due to anti-inflammatory agents serving as potential therapeutics of inflammatory respiratory disorders, the potential anti-inflammatory effects of IA warrant investigation.

The initial tissue that meets inhaled allergens is the respiratory epithelium, which has the ability to release mediators and cytokines (3). As a primary interface between the lungs and pathogens, epithelial cells lining the airways and alveoli provide a physicochemical barrier, responding to inhaled irritants by releasing various inflammatory mediators (4).

A number of proinflammatory cytokines and chemokines, consisting of interleukin (IL)-1, IL-6, IL-8, eotaxin, granulocyte-macrophage colony-stimulating factor, macrophage-inflammatory protein, and regulate on activation, normal T-cell expressed and secreted, as well as anti-inflammatory mediators, including prostaglandin E2 (PGE2) and nitric oxide (NO), are all synthesized by respiratory epithelial cells. The aforementioned cytokines and chemokines regulate inflammation by altering cell recruitment, activation and survival (5). It has been previously reported that the activation of respiratory epithelial cells is associated with respiratory disorders, including asthma, chronic obstructive pulmonary disease and cystic fibrosis, and also with respiratory infections. Respiratory epithelial cell stimulation via the use of inflammatory mediators results in the increased expression and secretion of a number of cytokines with proinflammatory functions (6). Of the chemical mediators that are secreted by the epithelial cells, prostaglandins serve an important role in the inflammatory processes of the respiratory system. Prostaglandins are synthesized from arachidonic acid through a reaction that is catalyzed by cyclooxygenase (COX). COX2, 
an isoform of COX, is an inducible enzyme and is expressed in response to inflammatory cytokines or lipopolysaccharide (LPS), the primary component that forms the outer membrane of gram-negative bacteria (7). Increased COX2 expression and PGE2 production has been observed to result from inflammatory respiratory diseases. When tracheal and pulmonary epithelial cells are induced to express COX2, they predominantly release PGE2 (8).

As a fundamental chemokine secreted by lung epithelial cells, IL- 8 serves a crucial function in the recruitment of inflammatory cells into the lung. The level of IL-8 produced is observed to correlate with the severity of lung injury (9). Several studies have suggested that the overexpression of IL-8 is essential to the pathophysiological changes observed in chronic inflammatory lung disease $(10,11)$. The level of IL-8 is reportedly a crucial prognostic factor for acute respiratory distress syndrome-associated mortality (12). The regulation of the respiratory epithelial cell IL- 8 response is therefore necessary to prevent excessive inflammatory reactions that are injurious to the lung. In acute lung injury, IL-8 production is reliant on gene products released during early inflammatory stages (13). In respiratory epithelial cells, the $\mathrm{NF}-\kappa \mathrm{B}$ pathway is activated, resulting in the translocation of cells to the nucleus, where they bind and activate the IL- 8 promoter. Therefore, the NF- $\kappa$ B pathway activates IL- 8 transcription. The maximal production of IL- 8 is dependent on cooperative interactions with the $\mathrm{NF}-\kappa \mathrm{B}$ signaling pathways (14). Furthermore, $\mathrm{NF}-\kappa \mathrm{B}$ is a ubiquitously expressed transcription factor family that regulates the expression of multiple genes that are involved in the inflammatory and immune responses, and also cellular proliferation (15).

In the present study, the effects of IA on COX2 expression, and IL-8 and PGE2 production were investigated through the selective modulation of $\mathrm{NF}-\kappa \mathrm{B}$ in the human pulmonary epithelial A549 cell line in vitro.

\section{Materials and methods}

Cell culture and chemicals. The human pulmonary adenocarcinoma epithelial A549 cell line and the human monocytic leukemia THP-1 cell line were purchased from the American Type Culture Collection (Manassas, VA, USA). Each cell type was suspended in Dulbecco's modified Eagle's medium (Gibco; Thermo Fisher Scientific, Waltham, MA, USA) incorporated with $4 \mathrm{mmol} / \mathrm{l} \mathrm{L}$-glutamine, $10 \%$ fetal bovine serum, $100 \mathrm{U} / \mathrm{ml}$ penicillin and $100 \mu \mathrm{g} / \mathrm{ml}$ streptomycin. Growing on culture dishes, the cells were left until they achieved a subconfluence of $80-90 \%$. Once this level had been reached, the cells were dissociated by treatment with $0.2 \%$ trypsin $/ 0.02 \%$ ethylenediamine tetraacetic acid for a total of $5 \mathrm{~min}$, and were subsequently collected by centrifugation at $300 \mathrm{x}$ g for $2 \mathrm{~min}$. The cells were plated at $2 \times 10^{4}$ cells $/ \mathrm{cm}^{2}$ on 24 -well plates, and were maintained for $48 \mathrm{~h}$ until they reached optimal confluence. Wu et al previously noted that A549 cells may respond to LPS when under serum-free conditions (8). To reduce the effect of serum-derived factors, the medium was replaced by a serum-free culture medium. The experiments were conducted $24 \mathrm{~h}$ later in the A549 cells.

IA with a purity of $>98 \%$ was purchased from Shanghai Tongtian Biotechnology Co., Ltd. (Shanghai, China). The IA was dissolved in dimethyl sulfoxide (DMSO) as a 100-mmol/1 solution for the treatment of the cells. LPS and pyrrolidine dithiocarbamate (PDTC) were obtained from Sigma-Aldrich (St. Louis, MO, USA). Polyclonal goat anti-mouse COX2 (cat.no.sc-23984; 1:800) and polyclonal rabbitanti-mouseNF- $\mathrm{B}$ p65 (cat. no. sc-372; 1:200) antibodies were purchased from Santa Cruz Biotechnology, Inc. (Dallas, TX, USA). Monoclonal mouse anti-human glyceraldehyde 3-phosphate dehydrogenase (GAPDH) antibodies (cat. no. kc-5G4; 1:10,000) were obtained from Kangchen Biotech Co., Ltd. (Shanghai, China) and monoclonal mouse anti-human toll-like receptor 4 (TLR4) antibodies (cat. no. 14-9917-80; 1:100) were purchased from eBioscience, Inc. (San Diego, CA, USA).

Cell viability assay. Cells in the exponential growth phase were seeded in 96-well culture plates $(5,000$ cells per well) and treated with various concentrations of LPS (1, 10 and $100 \mu \mathrm{g} / \mathrm{ml})$ and IA $(0.1,1,10$ and $100 \mu \mathrm{mol} / \mathrm{l})$ for 6,12 and $24 \mathrm{~h}$ and $24 \mathrm{~h}$, respectively. Following incubation, $20 \mu \mathrm{l}$ methylthiazol-tetrazolium (MTT) solution $(5 \mathrm{mg} / \mathrm{ml})$ was added to each well and the cells were incubated for a further $4 \mathrm{~h}$. The supernatant was then removed, and the resulting crystals were dissolved in DMSO. The absorbance of each well was measured using a VICTOR ${ }^{\mathrm{TM}} \mathrm{X}$ microplate reader (PerkinElmer Inc., Waltham, MA, USA) at $570 \mathrm{~nm}$. The cell viability was calculated using the following formula: Cell viability $(\%)=$ (average absorbance of treated cells / average absorbance of control cells) x 100. A lactate dehydrogenase detection kit (Reckon Diagnostics Pvt. Ltd., Vadodara, India) was used to evaluate the lactate dehydrogenase released from the cells following treatment with the different concentrations of LPS and IA. The kit was used according to the manufacturer's protocols.

Western blot analysis. Following treatment with the test agents, the cells were washed twice in phosphate-buffered saline and lysed in $400 \mu \mathrm{l}$ lysis buffer [62.5 mmol/1 Tris- $\mathrm{HCl}$ (pH 6.8), 2\% SDS, 10\% glycerol, $0.01 \%$ bromophenol blue and $5 \%$ 2-mercaptoethanol]. Western blot analysis was performed as described previously (16). Following this, the protein was separated using electrophoresis on a $10 \%$ polyacrylamide gel at $200 \mathrm{~V}$ for $80 \mathrm{~min}$. The protein was transferred to a polyvinylidene fluoride membrane, which was subsequently blocked and incubated with a specific goat polyclonal antibody against COX2 (1:800), a specific rabbit polyclonal antibody against $\mathrm{NF}-\kappa \mathrm{B}(1: 200)$ and a specific mouse polyclonal antibody against GAPDH (1:10,000). Chemiluminescence was observed using an enhanced chemiluminescence kit (GE Healthcare Life Sciences, Chalfont, UK). Quantitative analysis of the western blotting was performed using AlphaEase FC software (version 4.1.0; Alpha Innotech Corporation, San Leandro, CA, USA).

Enzyme-linked immunosorbent assays (ELISAs) for IL-8 and PGE2 production. Following treatment with the test agents, the cell culture medium was collected and the levels of IL-8 and PGE2 were measured using ELISAs; specifically, through the use of IL-8 and PGE2 assay kits (R\&D Systems Europe, Abingdon, UK), respectively. The assay was conducted by comparing the unlabeled IL-8/PGE2 in the sample and the fixed amount of labeled IL-8/PGE2. 


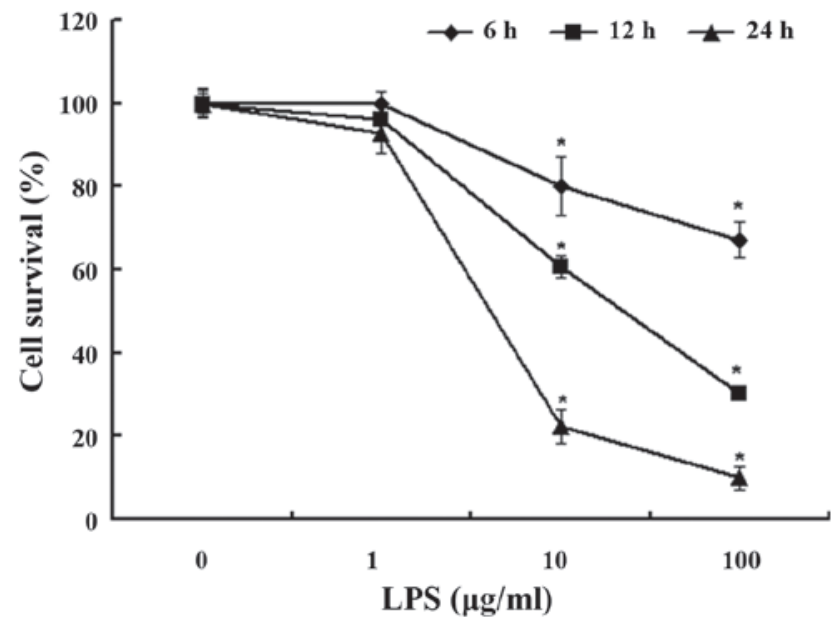

Figure 1. Effect of LPS on the viability of the A549 cells in culture. The cells were left untreated, or were treated with or 1,10 and $100 \mu \mathrm{g} / \mathrm{ml}$ LPS for 6,12 or $24 \mathrm{~h}$; cell viability was assessed using a methylthiazol-tetrazolium reduction assay. All data are presented as the mean \pm standard error of three separate observations. ${ }^{*} \mathrm{P}<0.05$ vs. without LPS. LPS, lipopolysaccharide.

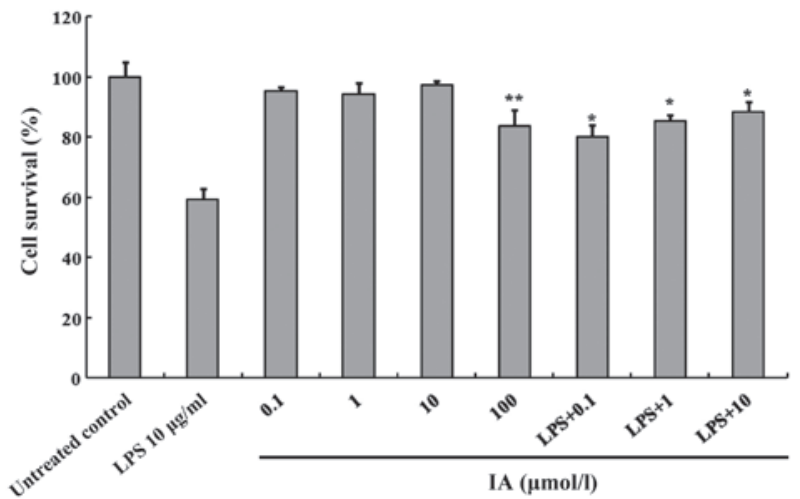

Figure 2. Effect of IA alone or the combination of IA and LPS on the viability of the A549 cells in culture. The cells were left untreated, or were treated with $0.1,1,10$ or $100 \mu \mathrm{mol} / 1$ IA for $12 \mathrm{~h}$. Cell viability was assessed using a methylthiazol-tetrazolium reduction assay. All data are presented as the mean \pm standard error of three separate observations. ${ }^{*} \mathrm{P}<0.05$ vs. LPS $10 \mu \mathrm{g} / \mathrm{ml}$ group. ${ }^{* *} \mathrm{P}<0.05$ vs. untreated control. LPS, lipopolysaccharide; IA, picfeltarraenin IA.

Statistical analysis. The data are expressed as the mean \pm standard deviation of at least three independent experiments. To determine the differences between the groups, Tukey's all pairwise comparison was used. All statistical analyses were performed using SPSS 16.0 statistical software (SPSS, Inc., Chicago, IL, USA). $\mathrm{P}<0.05$ was considered to indicate a statistically significant difference.

\section{Results}

Effect of LPS on A549 cell viability. To investigate the effect of LPS on the A549 cells, the cells were treated with 1, 10 and $100 \mu \mathrm{g} / \mathrm{ml}$ LPS at 6, 12 and $24 \mathrm{~h}$. Cell viability was observed using an MTT assay. The survival rate was $\sim 80 \%$ after $6 \mathrm{~h}$, $60 \%$ after $12 \mathrm{~h}$ and $22 \%$ after $24 \mathrm{~h}$ with LPS $10 \mu \mathrm{g} / \mathrm{ml}$ treatment (Fig. 1). The cell viability of the LPS-treated group was significantly decreased when compared with the untreated

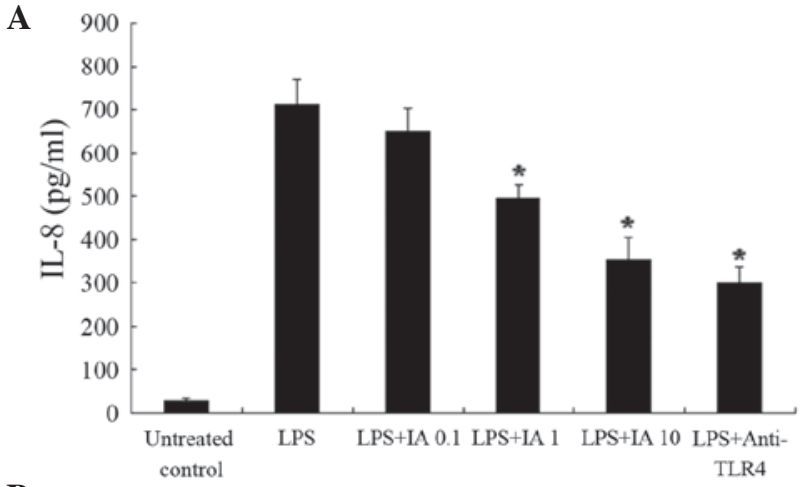

B

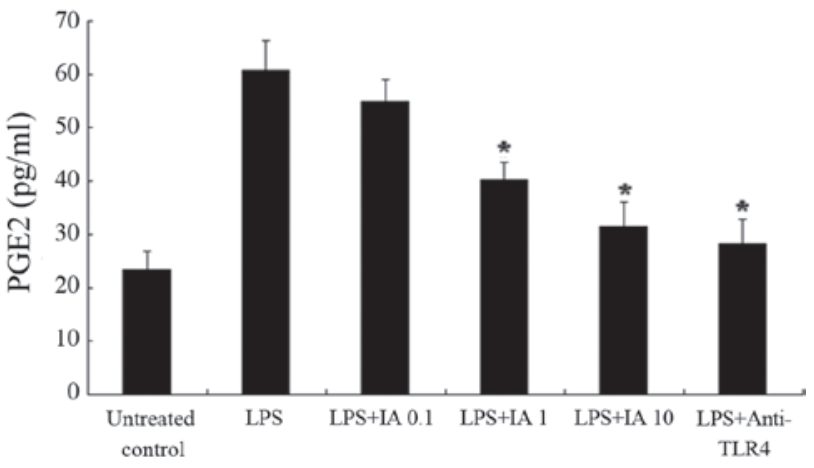

Figure 3. Effects of LPS, anti-TLR4 neutralizing antibody and IA on IL-8 and PGE2 production in the A549 cells. The cells were treated with $10 \mu \mathrm{g} / \mathrm{ml}$ LPS for $12 \mathrm{~h}$. An anti-TLR4 neutralizing antibody was added $1 \mathrm{~h}$ prior to the addition of LPS. IA $(0.1,1$, or $10 \mu \mathrm{mol} / \mathrm{l})$ was added concomitantly with LPS. Following treatment, the production of (A) IL-8 and (B) PGE2 was analyzed using an enzyme-linked immunosorbent assay. All data are presented as the mean \pm standard error $(n=4)$. ${ }^{*} \mathrm{P}<0.05$ vs. LPS alone. PGE2, prostaglandin E2; IL-8, interleukin-8; LPS, lipopolysaccharide; TLR4, toll-like receptor 4; IA, picfeltarraenin IA.

cells $(\mathrm{P}<0.05)$. These results suggest that the A549 cells were damaged by LPS in a dose- and time-dependent manner.

Effect of IA on A549 cell viability. The effect of IA on the viability of the A549 cells was subsequently investigated. The cells were incubated with varying IA concentrations for a period of $12 \mathrm{~h}$ in a serum-free medium. Cell viability was determined using an MTT reduction assay. As presented in Fig. 2, a concentration of $100 \mu \mathrm{mol} / \mathrm{l}$ IA was observed to significantly decrease cellular MTT reduction $(\mathrm{P}<0.05)$, but did not exhibit any toxicity at $\leq 10 \mu \mathrm{mol} / 1$. Additionally, IA was tested at $0.1-10 \mu \mathrm{mol} / 1$ to determine whether it improved LPS-induced cell inhibition. For this experiment, the A549 cells were treated with $10 \mu \mathrm{g} / \mathrm{ml}$ LPS in the presence or absence of IA at a concentration of $0.1-10 \mu \mathrm{mol} / 1$. IA significantly increased cell growth in the presence of $10 \mu \mathrm{g} / \mathrm{ml}$ LPS $(\mathrm{P}<0.05)$. The results suggested that IA possesses the ability to attenuate the cell injury induced by LPS.

Effect of IA on LPS-induced IL-8 and PGE2 production in A549 cells. LPS was used as an inflammatory agent in the subsequent experiment. To investigate the effect of IA on the production of LPS-induced IL-8 and PGE2 (a major COX product in A549 cells), $0.1-10 \mu \mathrm{mol} / 1$ IA was added concomitantly with $10 \mu \mathrm{g} / \mathrm{ml}$ LPS. The level of IL- 8 and PGE2 in the medium was quantitatively measured using an ELISA. As presented in Fig. 3, LPS significantly increased the amount of IL-8 and PGE2. 


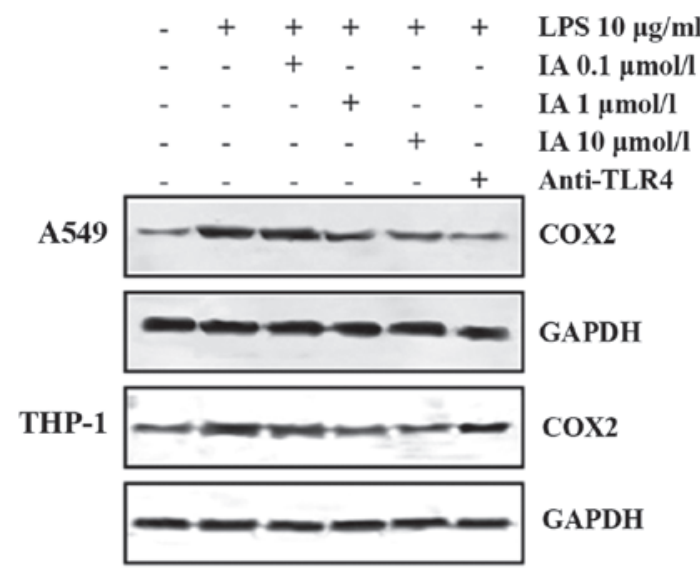

Figure 4. Effect of LPS and IA on COX2 expression in the A549 and THP-1 cells. The cells were treated with $10 \mu \mathrm{g} / \mathrm{ml}$ LPS for $12 \mathrm{~h}$. An anti-TLR4 neutralizing antibody was added $1 \mathrm{~h}$ prior to adding LPS. IA $(0.1,1$ or $10 \mu \mathrm{mol} / \mathrm{l})$ was added concomitantly with LPS. Following treatment, COX2 expression was analyzed using western blot analysis. LPS, lipopolysaccharide; IA, picfeltarraenin IA; COX2, cyclooxygenase2; TLR, toll-like receptor; GAPDH, glyceraldehyde 3-phosphate dehydrogenase.

A

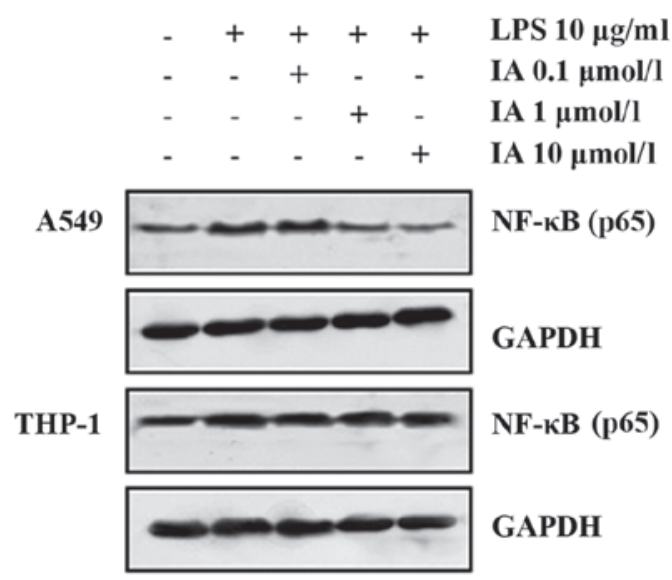

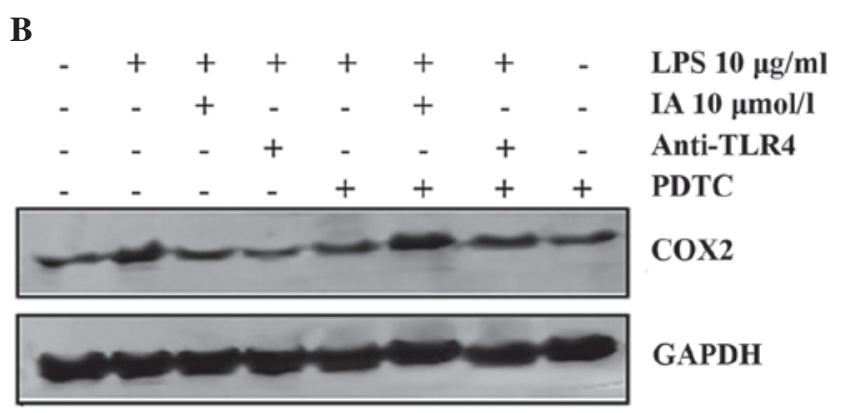

Figure 5. IA inhibits COX2 production via NF- $\kappa$ B. (A) IA suppressed the expression of NF- $\kappa$ B p65. The A549 cells were incubated with LPS in the presence or absence of IA, and subsequently processed for western blot analysis using antibodies against NF- $\mathrm{kB}$ p65. (B) IA inhibited LPS-induced COX2 by NF- $\kappa$ B. The A549 cells were treated with IA with or without PDTC. The level of COX2 was assayed using western blot analysis. LPS, lipopolysaccharide; IA, picfeltarraenin IA; COX2, cyclooxygenase 2; TLR, toll-like receptor; NF- $\kappa \mathrm{B}$, nuclear factor- $\kappa \mathrm{B}$; PDTC, pyrrolidine dithiocarbamate; GAPDH, glyceraldehyde 3-phosphate dehydrogenase.

The LPS-induced IL-8 production was significantly reduced by nearly 31 and $50 \%$ by 1 and $10 \mu \mathrm{mol} / 1 \mathrm{IA}$, respectively $(\mathrm{P}<0.05)$. $\mathrm{PGE} 2$ production was reduced significantly by nearly
34 and $48 \%$ by 1 and $10 \mu \mathrm{mol} / 1$ IA $(\mathrm{P}<0.05)$, respectively. In addition, TLR4, the primary receptor for the recognition of LPS on the cell surface, was used as a positive control. LPS-induced IL-8 and PGE2 production in the A549 cells was abolished by the presence of a neutralizing antibody against TLR4 $(20 \mu \mathrm{g} / \mathrm{ml})$.

Effect of IA on COX2 expression. To examine the sensitivity of A549 cells to LPS, the cells were incubated with LPS at a concentration of $10 \mu \mathrm{g} / \mathrm{ml}$ for $12 \mathrm{~h}$. COX 2 expression was analyzed using western blot analysis with anti-COX2 antibodies. As presented in Fig. 4, the expression of COX2 was significantly increased by treatment with LPS. The expression of COX2, induced by LPS, in the A549 cells was suppressed by the presence of a neutralizing antibody against TLR4, indicating that the response is mediated by TLR4 activation. Furthermore, LPS-induced COX2 expression was significantly inhibited by the presence of $10 \mu \mathrm{mol} / 1 \mathrm{IA}(\mathrm{P}<0.05)$ and was inhibited overall by IA in a concentration-dependent manner. To observe whether the aforementioned effect of IA was specific to the A549 cells, the human monocytic THP-1 cell line was also analyzed. As presented in Fig. 4, the expression of COX 2 in the THP-1 cells was substantially increased by treatment with LPS. The LPS-induced COX2 expression in the THP-1 cells was also inhibited by 1 and $10 \mu \mathrm{mol} / 1$ IA.

IA inhibits COX2 production through the $N F-\kappa B$ pathway. Expanding on previous studies that have reported NF- $\kappa \mathrm{B}$ activation as a key signaling mechanism of LPS-induced COX2 expression in A549 and RAW 264.7 cells (17), the molecular basis for IA inhibition of NF- $\mathrm{NB}$-mediated inflammatory cytokine production was investigated. Upon IA treatment, the LPS-induced NF- $\kappa \mathrm{B}$ was suppressed in the A549 cells $(\mathrm{P}<0.05)$, but not in the THP-1 cells (Fig. 5A). To confirm the inhibition of COX 2 production by the $N F-\kappa B$ pathway, the effect of IA treatment on LPS-induced COX2 in the A549 cells in the presence or absence of PDTC (a specific inhibitor of $N F-\kappa B$ ) was assessed. Fig. 5B demonstrates that IA inhibited LPS-induced COX2 production. Furthermore, PDTC (50 $\mu \mathrm{mol} / \mathrm{l})$ reversed IA-suppressed COX2 production in the A549 cells. Therefore, it can be concluded that IA suppresses $\mathrm{COX} 2$ production via the $\mathrm{NF}-\kappa \mathrm{B}$ pathway.

\section{Discussion}

IA was isolated and characterized from the whole plant of Picria fel-terrae Lour (18). However, the mechanism of IA is not well understood. The present study is the first of its type to investigate the immunoregulatory functions of IA on LPS-induced COX2, IL-8 and PGE2 responses in lung epithelial cells. Additionally, the study also established that the immunoregulatory effects of IA on LPS-induced epithelial cell responses are mediated partially by $\mathrm{NF}-\kappa \mathrm{B}$ inhibition.

The key finding of the current study was that IA significantly inhibited LPS-induced COX-2 expression, and IL-8 and PGE2 production in human pulmonary adenocarcinoma epithelial A549 cells. As the increased expression of COX2, and the production of IL-8 and PGE2 are indicated to serve an important role in airway inflammatory mechanisms, the inhibitory effect of IA may therefore facilitate the treatment of respiratory diseases. 
In the present study, LPS was employed to induce cytokine release in the A549 cells. The primary receptor for LPS is TLR4 (19), with its signaling requiring numerous accessory proteins, including cluster of differentiation (CD) 14 and lymphocyte antigen 96 (20,21). It has been previously reported that A549 cells respond to LPS through TLR4 in the presence of $1 \%$ serum, but that in the absence of serum they are unresponsive to LPS due to the low expression of CD14 and TLR4 (22). In the present study, the A549 cells responded to LPS and the response was subsequently blocked by an anti-TLR4 neutralizing antibody, therefore indicating that the A549 cell response is mediated by TLR4. The A549 cell cultures were moved to a serum-free medium $24 \mathrm{~h}$ prior to assays, however, serum influence may have remained in the cultures.

IL-8 is a chemokine that possesses a wide spectrum of responsibilities, including chemotaxis, cell adhesion, reactive oxygen species generation, angiogenesis promotion and azurophil granule release (23). Despite IL-8 being commonly recognized as a neutrophil-specific chemokine, it has also been indicated to modulate the function of a number of inflammatory cells, including $\mathrm{T}$ and B lymphocytes, natural killer cells, basophils, monocytes and eosinophils. The proinflammatory and regulatory cytokine IL- 8 can be identified in lung inflammation (24). In the present study, IA decreased LPS-induced IL-8 production in the A549 cells (Fig. 3A). PGE2 has been previously reported to activate IL- 8 gene expression in certain cell types. Prostaglandins, particularly PGE2 are produced in large quantities in osteoarthritic cartilage, and function as modulators of inflammation, inflammatory pain and tissue destruction (25). Prostaglandins are synthesized from arachidonic acid through the production of COX enzymes and prostaglandin synthases (26). The present study observed that IA also suppressed PGE2 production (Fig. 3B) and COX2 expression (Fig. 4). These results suggest that IA has possible anti-inflammatory effects.

A previous study (27) indicated that IA extracts suppressed the expression of COX2, the production of NO and PGE2, and the secretion of the proinflammatory cytokines IL-6, IL-8 and tumor necrosis factor- $\alpha$ in LPS-mediated RAW264.7 cells. Furthermore, these effects were demonstrated to be closely associated with the inhibition of the NF- $\kappa \mathrm{B}$ p50/p65 subunits (27). Therefore, in the present study, the effect on LPS-induced COX2 expression in THP-1 cells in the presence of IA was observed (Fig. 4). It has been reported that $\mathrm{NF}-\kappa \mathrm{B}$ is a key signaling mechanism in LPS-induced COX2 expression (28). IA is likely to act on these common mechanisms, thus inducing COX2 expression in the A549 and THP-1 cells (Fig. 4).

The present study has demonstrated that IA can downregulate IL- 8 and PGE2 production and COX2 expression via the pulmonary epithelial cell line in response to LPS. The results indicated that the mechanism of this modulation was partially initiated by NF- $\mathrm{B}$ inhibition. Further understanding of the molecular mechanisms by which inflammation is regulated in the lungs is required to aid the production of effective therapeutics that may eventually treat inflammatory lung diseases. Having demonstrated the possible advantages of the anti-inflammatory effects of IA for the treatment of respiratory disorders in the present study, future studies may decide to focus on the effects of IA using animal models of airway inflammation in vivo.

\section{Acknowledgements}

This study was financially supported by the Shanghai Natural Science Foundation (grant no. 15ZR1442000), the Budgetary Research Projects of the Shanghai Municipal Education Commission (grant no. 2014YSN41) and the Doctoral Fund of the Ministry of Education of China (grant no. 20123107120010).

\section{References}

1. Wen L, Wei Q, Chen G, Liu F, Zhang S and You T: Bioassay and liquid chromatography/mass spectrometry-guided acetylcholinesterase inhibitors from Picriafel-terrae. Pharmacogn Mag 9 (Suppl 1): S25-S31, 2013.

2. Ueki T, Akaishi T, Okumura $\mathrm{H}$ and Abe K: Extract from Nandina domestica inhibits lipopolysaccharide-induced cyclooxygenase-2 expression in human pulmonary epithelial A549 cells. Biol Pharm Bull 35: 1041-1047, 2012.

3. Bals R and Hiemstra PS: Innate immunity in the lung: How epithelial cells fight against respiratory pathogens. Eur Respir J 23: 327-333, 2004.

4. Skerrett SJ, Liggitt HD, Hajjar AM, et al: Respiratory epithelial cells regulate lung inflammation in response to inhaled endotoxin. Am J Physiol Lung Cell Mol Physiol 287: L143-L152, 2004.

5. Cornell TT, Hinkovska-Galcheva V, Sun L, et al: Ceramide-dependent PP2A regulation of TNFalpha-induced IL-8 production in respiratory epithelial cells. Am J Physiol Lung Cell Mol Physiol 296: L849-L856, 2009.

6. Abate W, Alghaithy AA, Parton J, Jones KP and Jackson SK: Surfactant lipids regulate LPS-induced interleukin-8 production in A549 lung epithelial cells by inhibiting translocation of TLR4 into lipid raft domains. J Lipid Res 51: 334-344, 2010.

7. Chen H, Ma F, Hu X, Jin T, Xiong C and Teng X: Elevated COX2 expression and PGE2 production by downregulation of $\mathrm{RXRa}$ in senescent macrophages. Biochem Biophys Res Commun 440: 157-162, 2013.

8. Wu S, Duan S, Zhao S, et al: Atorvastatin reduces lipopolysaccharide-induced expression of cyclooxygenase-2 in human pulmonary epithelial cells. Respir Res 6: 27, 2005.

9. Lin CH, Nai PL,Bien MY, Yu CC and Chen BC: Thrombin-induced CCAAT/enhancer-binding protein $\beta$ activation and IL-8/CXCL8 expression via MEKK1, ERK, and p90 ribosomal S6 kinase 1 in lung epithelial cells. J Immunol 192: 338-348, 2014.

10. Lin $\mathrm{CH}$, Yu MC, Chiang CC, et al: Thrombin-induced $\mathrm{NF}-\kappa \mathrm{B}$ activation and IL-8/CXCL8 release is mediated by c-Src-dependent Shc, Raf-1, and ERK pathways in lung epithelial cells. Cell Signal 25: 1166-1175, 2013.

11. Maza PK, Oliveira P, Toledo MS, et al: Paracoccidioides brasiliensis induces secretion of IL- 6 and IL- 8 by lung epithelial cells. Modulation of host cytokine levels by fungal proteases. Microbes Infect 14: 1077-1085, 2012.

12. Hildebrand F, Stuhrmann M, van Griensven M, et al: Association of IL-8-251A/T polymorphism with incidence of Acute Respiratory Distress Syndrome (ARDS) and IL-8 synthesis after multiple trauma. Cytokine 37: 192-199, 2007.

13. Bao Z, Ye Q, Gong W, Xiang Y and Wan H: Humanized monoclonal antibody against the chemokine CXCL-8 (IL-8) effectively prevents acute lung injury. Int Immunopharmacol 10: 259-263, 2010.

14. Choi KC, Lee YH, Jung MG, et al: Gallic acid suppresses lipopolysaccharide-induced nuclear factor-kappaB signaling by preventing RelA acetylation in A549 lung cancer cells. Mol Cancer Res 7: 2011-2021, 2009.

15. Liu L, Gu H, Liu H, et al: Protective effect of resveratrol against IL-1 $\beta$-induced inflammatory response on human osteoarthritic chondrocytes partly via the TLR4/MyD88/NF- $\kappa \mathrm{B}$ signaling pathway: An 'in vitro study'. Int J Mol Sci 15: 6925-6940, 2014.

16. Zhou QM, Wang XF, Liu XJ, et al: Curcumin improves MMC-based chemotherapy by simultaneously sensitising cancer cells to MMC and reducing MMC-associated side-effects. Eur J Cancer 47: 22402247, 2011. 
17. Du X, He S, Jiang Y, Wei L and Hu W: Adiponectin prevents islet ischemia-reperfusion injury through the COX2-TNF $\alpha$ $\mathrm{NF}-\kappa \mathrm{B}-$ dependent signal transduction pathway in mice. $\mathrm{J}$ Endocrinol 218: 75-84, 2013.

18. Zou JM, Wang LS, Ma XM, Guo YJ and Shi RB: A new cucurbitacin from Picria fel-terrae. J Asian Nat Prod Res 8: 367-371, 2006.

19. Medzhitov R, Preston-Hurlburt P and Janeway CA Jr: A human homologue of the Drosophila Toll protein signals activation of adaptive immunity. Nature 388: 394-397, 1997.

20. Frey EA, Miller DS, Jahr TG, et al: Soluble CD14 participates in the response of cells to lipopolysaccharide. J Exp Med 176: 1665-1671, 1992.

21. Shimazu R, Akashi S, Ogata H, et al: MD-2, a molecule that confers lipopolysaccharide responsiveness on Toll-like receptor 4. J Exp Med 189: 1777-1782, 1999.

22. Thorley AJ, Grandolfo D, Lim E, et al: Innate immune responses to bacterial ligands in the peripheral human lung - role of alveolar epithelial TLR expression and signalling. PLoS One 6: e21827, 2011.

23. Hay DW and Sarau HM: Interleukin-8 receptor antagonists in pulmonary diseases. Curr Opin Pharmacol 1: 242-247, 2001.
24. Mukaida N: Pathophysiological roles of interleukin-8/CXCL8 in pulmonary diseases. Am J Physiol Lung Cell Mol Physiol 284: L566-L577, 2003.

25. Vuolteenaho K, Koskinen A, Kukkonen M, et al: Leptin enhances synthesis of proinflammatory mediators in human osteoarthritic cartilage - mediator role of NO in leptin-induced PGE2, IL-6, and IL-8 production. Mediators Inflamm 2009: 345838, 2009.

26. Higaki T, Okano M, Fujiwara T, et al: COX/PGE(2) axis critically regulates effects of LPS on eosinophilia-associated cytokine production in nasal polyps. Clin Exp Allergy 42: 1217-1226, 2012.

27. Yang DJ, Chang YY, Lin HW, Chen YC, Hsu SH and Lin JT: Inhibitory effect of litchi (Litchi chinensis Sonn.) flower on lipopolysaccharide-induced expression of proinflammatory mediators in RAW264.7 cells through NF- $\mathrm{BB}$, ERK, and JAK2/STAT3 inactivation. J Agric Food Chem 62: 3458-3465, 2014.

28. Lee KH, Yeh MH, Kao ST, et al: Xia-bai-san inhibits lipopolysaccharide-induced activation of intercellular adhesion molecule-1 and nuclear factor-kappa B in human lung cells. J Ethnopharmacol 124: 530-538, 2009. 